\title{
Astronomischer Jahresbericht
}

Gegründet von Walter F. Wislicenus

Mit Unterstützung der Astronomischen Gesellschaft

herausgegeben vom

Astronomischen Rechen-Institut

in Heidelberg

50. Band

Die Literatur des Jahres 1950

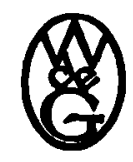

In Kommission bei

Walter de Gruyter \& Co.

vormals G. J. Göschen'sche Verlagshandlung - J. Guttentag, Verlaggbuchhandlung - Georg Reimer - Karl J. Trübner - Veit \& Comp. 
Alle Rechte rorbehalten

Archiv-Nr. 180153

Gedruckt mit Unterstützung der Deutschen Forschungsgemeinschaft

Druck G. Braun (vorm. G. Braunsche Hofbuchdruckerei und Verlag) G.m.b.H. Karlsruhe in Baden

Printed in Germany

Auflage 600 - April 1953 